\title{
History, Fandom, and Online Game Communities
}

\section{Nick Webber and E. Charlotte Stevens}

\section{Introduction}

I was one of the two primary infiltrators and operatives involved in this heist, working closely with Arenis Xemdal to gently guide UQS [Ubiqua Seraph] towards realizing he was the most competent person in the corporation and that they should do everything he said without question.

People speculated at the time that what we stole was worth approximately 16500 USD, I never bothered to do the math myself so don't know if that's true.

(Thorrk 2013).

In this chapter, we are concerned with the people who play, or otherwise engage with, video games in order to undertake what we might think of as historical work. Accordingly, our focus is not on games as representational spaces in which we might, or might not, find history. These players produce outputs of various kinds that are concerned with their own pasts in relation to these games. These are positioned in a range of different spaces, including professionally published books, game journalism sites and personal blogs, along with selfdescribed 'history' wikis and 'fan' archives. The different natures of these online spaces reflect different ways of framing and understanding this player productivity, creating uncertainty about the place of this material within established intellectual frameworks and 
disciplines. We ask, therefore, how these practices are best understood: as 'history' or as 'fandom', as both or as neither? We argue that they sit at the intersection of historical and fan activity, in many cases sharing the qualities of both kinds of productive engagement. This is not, of course, to say that history and fandom are the same thing, but to further conceptualise the relationship between these two constructions and their attendant scholarly disciplines. The extract above concerns an event which took place in 2005. It is drawn from an account produced in 2013 as part of 'True Stories from the First Decade', a promotional campaign around the online game EVE Online which aimed to capture some of those player experiences for which the game has become famous. True Stories is one of a slew of ostensibly historical activities which have taken place around EVE (see Webber 2016), aimed at capturing the past of the game's communities. These include Andrew Groen's 'History of the Great Wars of EVE Online' (2015); a now-defunct wiki devoted to EVE History; a range of blog and forum posts discussing $E V E$ 's past; and long-form journalistic accounts of EVE's military campaigns. In a similar manner, other massively multiplayer online games, such as EverQuest and World of Warcraft, have player communities which produce engagements with their past both within and around the game. Although much of this material is pitched in terms of memory rather than of history - as reminiscence, perhaps, or memoir - in aggregate, it comprises a broad landscape of public historical work taking place within and around these online spaces. Indeed, Josh Howard (2018) entitled his attempt at capturing EverQuest's past 'Public History Norrath'.

While projects such as True Stories and Public History Norrath mark attempts to capture these pasts within a more or less explicitly game-historical frame, we can of course find extensive bodies of game-related, player-produced work elsewhere. Archive of Our Own, for example, is 'a multifandom database' and 'archive for fan fiction' (De Kosnik 2016, 93) that contains more than 50,000 fan-created artefacts focused on the Dragon Age series of games 
as of 11 April 2018, with fanworks based on the Mass Effect series accounting for a further 17,000 contributions (figures drawn from Archive of Our Own 2018). ${ }^{1}$ Only some of this material concerns itself with any form of past, but that which does so both reflects and demonstrates a discursive engagement with a series of pasts, this time captured within the OTW's broader project to 'preserv[e] the history of fanworks and fan culture' (2018). It is tempting to frame all of these activities as forms of public history, following Kean and Ashton $(2009,1)$ in thinking of this as historical work which breaks down the distinction between historians and their publics, democratising our relationship with the past. Yet we cannot escape the fact that this work also sits within a space more often thought of in terms of fandom than of history, not only in consideration of where it can be found - in places like Archive of Our Own, on game-focused wikis, blog and forums - but also in its relationship to 'overtly "participatory” or “productive” fan works' (Click and Scott 2017, 2) orientated towards corporately-owned intellectual property. They have been described in one instance as 'the historical practices of fan cultures surrounding ostensibly non-historical games' (Chapman, Foka and Westin 2017, 361), a tidy formulation which offers a resolution, even as it implies some distance between communities of ('proper', or more traditional) historians and fan cultures. Situation in the space of fandom, then, distinguishes this work in some manner from other, more orthodox, historical practices. ${ }^{2}$

\section{How history is used}

\footnotetext{
${ }^{1}$ By comparison, there are more than 160,000 works in that archive focused on the Harry Potter franchise.

${ }^{2}$ We might be prepared to think of the scholarly discipline of history as, amongst other things, 'fandom of the past', echoing previous claims that humanities scholars are fans of cultural theory (McKee 2007) and naming those who participate in high culture as 'fans' of Bach, or Shakespeare (Pearson 2007), or Chekov (Tulloch 2007).
} 
Discussion about these activities is important not only because it draws out the value in different forms of engagement in culture, but also because it helps us to understand how history is put to work - as a discipline, as a set of ideas, and as a collection of practices. Within the discipline of history, the 'conceptual anarchy' identified by Hayden White (1973, 13) persists, drawn out not only by the advent of online activity, greater information sharing, and increasing levels of popular engagement with the past, but also by a contemporary political landscape in which histories continue to be deployed to support agendas of nationalism and marginalisation. Here, we seek to contribute to the discipline through understanding more about how communities make use of ideas which are central to historians' own engagement with the past - accuracy, for example, or interpretation. Historical game studies rests upon the premise that video games afford the potential to change how people - both players and historians alike - engage with and learn about the past. Considerations about the extent to which these activities 'count' as history and/or as fandom have the potential to affect how we respond to them, how we learn from them as scholars, and the extent to which we value them as historical engagement.

We have thus approached this topic from different directions - one of us from history, the other from fan studies - to try to understand how these two fields come together, and how the ideas from them overlap. The extent to which game communities engage in historical work is increasingly important to both of our research. Independently, in other work, we have made arguments which bear directly on this discussion. Webber $(2016 ; 2017)$ has argued that activities like True Stories, and the work and attention that underpin them, can be thought of as history, meeting definitions advanced by a range of historians, including not only White (1973; 1990), but also, for example, E.H. Carr (1990) and Keith Jenkins (2003). Thus, this activity - this history - engages with the past to make truth claims, demonstrates an engagement with the past of people in society, and represents a discourse about that past. 
Conversely, however, at the end of an analysis of the journalistic work that takes place in the EVE Online community, he has suggested that such journalism 'produces not a fan history of EVE, but a history of a particular form of EVE fandom' (Webber 2017, 105). In a similar manner, in her investigation of the fan practice of 'vidding' - the production of a 'montage of extracts from media in a personal archive' $(2017,143)$ - Stevens has argued that fanvids should be understood as histories in themselves, in their presentation and interpretation of a number of different pasts.

In what follows, then, we will consider the relationship between fan practices and historical work through the idea and role of the historian, concepts of accuracy, and the relationship between curation and interpretation. Notably, the practices and material we will discuss sit at a number of conceptual intersections beyond that of fandom and history. Firstly, a division is sometimes made between the 'real' and the 'virtual', under which video games are virtual environments, and thus video game experiences are, for many, 'virtualised'. ${ }^{3}$ Secondly, and relatedly, is a distinction between the fictional past of a gameworld - often referred to as 'lore' - and the past of its players. Lore is, in this analysis, a diegetic history to some extent; but we must be mindful that the diegesis of a game is not always fixed, and may be shaped at least in part by the agency of its players. In any case, players' accounts of their experiences, as shared in both online and offline spaces, often show little regard for any of these distinctions, shifting freely across these divisions and embedding play experiences within and beyond the gameworld and its lore. This is often done in a manner which can make it difficult to be sure of the context in which activities occurred:

Plans were made throughout the day on coalition command about which timers we would focus on and where we would choose to strike. A general meeting was also

\footnotetext{
${ }^{3}$ A position common, for example, in earlier game studies scholarship - see Lehdonvirta 2010. This is explored in respect of EVE Online in Carter et al. 2016.
} 
held among the Vale commanders to determine priorities and strategies. I chewed threw [sic] all but the last couple episodes of Daredevil and ate delicious and unhealthy chicken wings while I waited for the fun to begin.

(Vily 2016).

\section{If this is history, where are the historians?}

A key element in our consideration of the intersection between history and fandom lies in the concept of the historian as a figure who structures the mediation between a society and its past. As we have already suggested, there are individuals at work through game communities who we might see in this role: Andrew Groen has been called 'EVE Online's Historian' (Warr 2015), for example, and Josh Howard curates Public History Norrath. Elsewhere, there are numerous agents who have prompted and shaped discussions about the past in forums, on news sites, and in wikis. While these individuals' interventions vary in scope, they act as catalysts for past-focused engagement, in the manner of public historians who stimulate the relationship between histories and their publics. In $E V E$ in particular, there has been a notable attachment of importance to history and historians - one commentator, for example, observed that 'EVE needs historians' (Pirannha, comment on Fiddle 2013), while another noted the importance of stories from the past in constructing identity - 'it's important for us, to know where we came from' (Spiegel-XI, debate point 1741 on Gianturco 2013). Within fan practice more generally, the Organisation for Transformative Works positions itself in the role of the historian (or at least historical institution), in its attempts to capture the history of fandom and fanworks. The OTW was founded by fans, many of whom are academics but notably not academic historians, and its historical activity extends beyond Archive of Our Own to include the historically-oriented Fanlore wiki, alongside other fandom-related advocacy. 
Yet while there are a number of individuals and institutions that we can identify as historians, such explicit identification is the exception rather than the rule in the communities under consideration. This does not necessarily indicate that historical work is not taking place, or that individuals and groups are not 'doing history'. In the space of MMORPGs, and related virtual worlds, there is a broad range of activity which aims to capture specific pasts, through the production of memoirs (from Second Life, for example), of organisational histories (around guilds, clans and corporations, across a selection of online games), or accounts of notable 'game' moments (for example, the autobiographical account of a player who broke the in-game economy of Star Wars Galaxies; see Desjardins 2012). Within media fandom, accounts added to Fanlore pages or accumulated in Tumblr threads tend to be framed as lists of events, with autobiography removed from accounts except as contextualising citations, thereby constructing fandom's history as a shared experience. How do we decide to what extent such contributors 'count' as historians or 'simply' as fans? Does according one status to them diminish them in light of the other, given, for example, perceptions that professional historians are the only legitimate bearers of knowledge of the past (Kean and Ashton 2009, 67)?

Public history, as a more organic and democratic form of historical knowledge, offers an intellectual framework comfortable both with or without distinctly identified (or even identifiable) historians (Kean and Ashton 2009, 1-2). As Raphael Samuel had it, history is the work of many 'invisible hands': 'if history was thought of as an activity rather than a profession, then the number of its practitioners would be legion' $(1994,17)$. To understand these individuals in this way is also to understand them as contributors to the historical 'needs' of their communities - active participants in the creation of a usable past, focused in the present. This in itself is to see them within a framework of historical engagement which echoes the public response to the past observed by Rosenzweig and Thelen (1998), and 
reminds us of Jenkins' insistence that historical discourse is created by 'present-minded workers' $(2003,31-2)$. We can reason from this position that historians, as mediators of the past, might emerge from publics of all kinds in response to perceived 'historical needs'. Within player communities - player publics — these needs could arguably be met by public historians of fandom who also retain the quality of being fans.

We cannot, however, beg the question of the status of the past-focused output of these player publics. While public historians can also be or act as fans, it is also quite possible for them to just act as fans. Furthermore, accepting this dual status as fans and historians echoes concerns in fan studies about how academics might create critical distance between themselves and their object of fandom. ${ }^{4}$ Even setting this aside, the nature of public historical work can often operate to reduce the stature of this form of enterprise. Taking True Stories as an example, should this be thought of as history, its publication as a graphic novel would set it firmly into the category of 'not proper history' for those who expect 'history' to be presented in more traditional forms (e.g. textbooks: see Chapman 2016, 6). Its credibility as history (although notably, not as fandom) is reduced by the mediation of its telling (Webber 2016, 202).

Thus while these communities can arguably produce historians, who in turn generate an extensive variety of material about the past, we must still consider whether or not these are engaged accounts that can be understood as usable, public pasts for those in the present (see Jordanova 2006, 131-3). This requires them to have stature as history within their publics, beyond the typicalities we might associate with fan practice and production, and in their most productive and radical form, to be 'politically self-conscious, community-based histories, open to all and usable in political struggles' (Jordanova 2006, 126). We therefore turn from

\footnotetext{
${ }^{4}$ On which, see Hills (2002) on aca-fan identities; and Brooker, Duffett and Hellekson (2017) on negotiating ethnographic methodologies in doing fan studies research.
} 
the producers to the work itself, and the ways in which our 'fan-historians' relate to their objects of interest.

\section{Curation}

The release of Deception (Dietz 2012), a novel set in the Mass Effect universe, prompted a torrent of fury from fans of the game (and of its broader, transmedia manifestations), which at its height included the production of a detailed 15-page exposition of every single perceived miss-step in the book, when considered in the light of other narratives of and about Mass Effect (nightrapt0r 2012). This document's authors note that it lists 'errors' of different magnitudes; problems and 'oddities' with game lore — the past of the game world — are the most extensive (running to more than 8 pages in all), but issues are also raised with characters, technology, and even the book's timeline. The significant attention to detail demonstrated here evokes stereotypical depictions of fans and their attitudes towards cultural properties: an almost obsessive concern with precision and correctness. That much of this attention is focused on Mass Effect's lore, its diegetic past, makes immediate and direct connection with the work of historians, expected to provide 'accurate and convincing accounts of the past' (Jordanova 2006, 62). Deception, as a new, 'fictive' intervention in the Mass Effect universe, is critiqued for its relation to what is currently considered 'known', in a manner similar to that of a historian (or history fan) critiquing a work of historical fiction. This form of 'protective' fan activity has come to be known as 'curatorial' or 'affirmational' practice (Russo 2010; Jenkins et al. 2013; Scott 2013; Kohnen 2017). History, too, has long been understood as a curatorial practice, something seen clearly in Carr's presentation of a (professional) historian as someone who selects and orders 'historical facts' to produce history (Carr 1990, 7-30). Importantly, these practices of selection are judicious — grounded in expertise, and understood to lend significance to the item or items selected. As Carolyn Steedman $(2001,66-88)$ notes, though, these selections are not made from all possible 
material, but rather from conscious and accidental deposits that amount to little more than 'traces and fragments' of past documentation.

In a similar manner, those in pursuit of a curatorial mode of fandom seek to master and control the information and objects available to them, ordering and displaying this material to other fans. 'Affirmation' describes the manner in which this activity reinforces and supports the narrative of the core property, a mode of fandom 'which seeks to construct its fantasies within the terms created by the original text' (Jenkins et al. 2013, 150), and 'is characterized by a deep investment in both authorial intent and the "rules" that govern a fictional universe, along with a desire to comprehensively understand that universe' (Scott 2013, 321). This practice of display thus establishes not only the status of a fan within the community but also adds significance to the status of the fan objects themselves. In both communities, such curatorial acts establish an agreed range of significant knowledge.

\section{Accuracy}

In the space of both history and fandom, there is a communal, discursive process through which knowledge is produced. Historical facts, according to Carr, require not only to be proposed for membership of the 'select club of historical facts', they also require 'a seconder and sponsors' (Carr 1990, 12). As we can see in the case of Deception, the boundaries of this knowledge are policed, and this occurs more or less aggressively depending upon the context. Accuracy seems as important to Mass Effect fan-historians, as it is to non-fan-historians.

While the idea of the historian as an objective seeker-after-truth may have been dismantled in recent decades (e.g. Jordanova 2006, 87-90), important disciplinary principles of evidencebased enquiry remain; evidence is drawn from sources which are analysed and critiqued. In fandom, these sources are a series of texts, considered as the 'canon' of a particular fan property, usually 'official' or 'approved' accounts of the storyworld. 
The attention to the past within video game communities is often complicated by a blurring of boundaries between the game property (as produced by the game developer and publisher) and the experiences of players themselves (see, for example, Hardin 2013). Fans' curatorial practices may thus be played out in more complex terrain than that of a novel couched entirely within the frame of game lore. Strikingly different discourses about the past emerge in blog posts anchoring a community's play experience in lore, and in the politically-focused oral histories of Groen's Empires of EVE. The Mass Effect fans act, as a community, to hold the knowledge presented in Deception to account, in relation to a form of canonical information. In doing so, they perform the quality of their attention and mastery. Histories of Norrath and New Eden (the EVE universe), conversely, present a discourse about the past which is, in itself, a collation of a series of separate and distinct discourses.

The interaction of such discourses is clearly evident in the player activity around the True Stories project. While each story contributed serves as a summary of an individual view on an event or series of events, the site provided space for discussion and comment, and here we see what is recognisable as a variety of forms of historical discourse. In these comments, players not only talk about the accuracy of a presented past, they argue over both it and its purpose. Perceptions that some pieces of writing are biased, or propagandistic, are communicated throughout; with accounts referred to, for example, as 'over exaggerated chest beating' (Kazellis, debate point 1661 on Gianturco 2013) or 'a one sided propaganda view on what happend [sic], stretching the truth in actual events' (Powers, debate point 1570 on Gianturco 2013). Here, we see evidence of the historical not simply in the relationship of these stories to a specified past, but in the fact that that past is open for negotiation. Concerns of propaganda indicate a further historical sensibility: this is a past being made useful, being put to work. 
In these different ideals of accuracy, we can see a division between historical accuracyproduced through consensus, but ultimately open to challenge; and fan accuracy—produced with reference to an unassailable, absolute text, its authority deriving not from community verification but from the owner of the fan property. The response to Deception suggests there is room for negotiation only in the moment of addition to the canon. For historians, however, this is the point at which negotiation would normally begin. While traditionally bound to narrative, historians have come to reject many of its sureties; fan-historians, conversely, often hold tightly to them.

\section{Interpretation and transformation}

Although the curatorial practices evident in both fan and historical work can be characterised by a process of selecting and bringing together information, this is only part of the discussion. When Groen drew together his history of $E V E$, he was synthesising a number of discourses about that particular past into an interpretative document in which he draws out understanding from the evidence before him. Indeed, such interpretation is normally considered a core component of curatorial practice; museums, for example, both exhibit and interpret their items. This is also indicated clearly in Carr's discussion: 'The belief in a hard core of historical facts existing objectively and independently of the interpretation of the historian is a preposterous fallacy, but one which is very hard to eradicate' $(1990,12)$. While, as we have seen, there is significant attention in fan communities to a curatorial mode, the production of interpretative texts which address the 'gaps' within the curated past, for example, is known as transformative fandom: a space in which canonical texts can be both bolstered and challenged through creative responses (fanfiction, fan art, vidding, etc.). As with historical video games themselves, there is a strong presence here of alternative narratives of the past. 
The distinction between curatorial and transformative modes is a relatively recent way of accounting for different fan practices. The curatorial mode values mastery over the rules of a storyworld, but 'transformative fandom [...] values "appropriation over documentation, and multiple interpretations over hierarchical authority"' (Scott 2013, 321, citing Julie Levin Russo). Each piece of fanfiction takes a set of characters and scenarios and, for example, offers versions of characters' stories before, during, or after canonical events. Separate fanvids use common footage to construct individual affective accounts of gameplay; the same significant clip will often be used in multiple vids. Thus, transformative fanworks exist in the spaces within and between canonical texts; they are textualised acts of interpretation which draw out and explore the potentials of the lacunae in the authorised narrative.

As a process, this is highly reminiscent of the practices of historians. When confronted with a gap in their sources, historians also work to address it through interpretation and argument, working from its limits to produce a reasonable and possible understanding of what 'actually happened'; or, in another view, what 'might have been'. Yet while, in the space of history, that latter phrase reflects the uncertainty that often exists around historical knowledge, in fandom it echoes the way in which transformative fan practices run against industry-led transmedia storytelling. In these forms of fandom, canon acts as scaffolding to build something new: knowing your 'history' matters, but interpreting those events is what lies at the core of transformative fan practice. Within this framework, EVE's True Stories hold only as much authority as any other industry-sanctioned paratext. Thus both fandom and history rely on interpretation and reinterpretation in relation to accepted points of authoritative knowledge. Again, this interpretation does not take place in isolation and both forms of work require validation from the community to obtain purchase with an audience.

Concepts of interpretation may also present an interesting challenge to the 'historicity' of the material we are concerned with here. While many spaces gather and display 'historical' 
material, relatively few offer interpretation across that material unless it is interpretative in and of itself (for example, a player account which extends the lore). Interpretative work takes place in a number of $E V E$ 's spaces but is scarce elsewhere. It appears in True Stories, as a player contribution (e.g. Gianturco 2013) is subject to commentary from the community and then transformed into a graphic novel (Way et al. 2014); and in EVE's journalism, as accounts of events are incorporated into long-form narratives of in-game wars. Public History Norrath offers neither synthesis nor interrogation of the accounts presented, nor does it seek to contextualise these contributions within a broader project. 'History' blogs often post a few accounts and then go silent, leaving, in effect, 'raw' source material. Conversely, transformational fandom seems often to reinterpret (or reject) canonical material almost as a reflex; no community-held knowledge is sacred, nothing ever agreed. In this respect, much of our material might be seen as archive rather than history or fandom: the material from which history or fanworks are made, but lacking that final step of contextualised and structured interpretation, or creative transformation. With that said, we must bear in mind that, for some players at least, their experiences 'felt like making history' (Anon 2015).

\section{History, fandom, archive?}

Although it is possible to make simple distinctions between the idea of a canon as something either created or transformed but ultimately authoritative, and a discursive landscape within which nothing is beyond challenge if the evidence presents itself, this does not support a clear distinction between fanwork and historical work. Different forms of fanwork, both affirmational and transformative, demonstrate practices which we can recognise in historical work, and behaviours which we might think of as 'historical' (although as we suggest, the idea of the 'curatorial' used in fan discussion is perhaps too narrowly pitched). An overlap exists between the practices of history and fandom, personified by fan-historians in some of their approaches to knowledge and in some of those activities which bring 
together player experiences with the strictures of lore. Thus, while activity around EVE seems to carry more easily-recognisable trappings of history - is perhaps more obviously 'historical' - than that around other games, it may simply represent one end of a spectrum of activities performed by the fan-historical community. Equally, while the treatment of Mass Effect presented here shows clearly how affirmative fandom can function in relation to a form of past, this is not to say that Mass Effect is a less historical space than, say, EverQuest is, although there may be less evidence of public historical work in the Mass Effect community. Those pasts which emerge directly from player experience-in effect, those of the communities around persistent, massively multiplayer online games - may have a stronger claim to be historical than those from other games. This distinction is perhaps most pronounced in situations where games offer a 'sandbox' space, rather than one bounded by narrative (to which, as we suggest, historians seem less wedded than fans, with implications for fan-historians).

The blurring between registers and different forms of experience, seen in Vily's account quoted above, defines a particular context for thinking about these activities specifically as forms of public history. The affective qualities of public history are widely recognised; it draws strongly on the direct connection of a public to its past, and relies not only on the engagement formed by a sense of investment in past events and their consequences, but also in a sense of legitimacy in accounts of those events. The experiential turn in historical work allowed for a far more explicit attention to accounts which privileged this kind of legitimacy, such as oral histories of direct, personal experience. A conceptual challenge arises, though, when an experiential account moves fluently between the fictional and the factual. For the historical endeavours of these player communities, the encroachment of fiction is accepted; indeed, in $E V E$, fictional spaceships are markedly more important than factual chicken wings. There is evidence that a personal attestation of presence — witnessing — is central to such 
discussions, leading players to attest to the 'realness' of their experience (Carter, et al. 2016). This lays claim to a particular form of cultural historical authenticity which differs markedly from the kinds of representational historical authenticity we normally think about in terms of games. Importantly, and like fan practice, it is grounded in affective engagement.

The idea that fans might be deeply invested in an authoritative position on the past of their property of choice resonates strongly with the disciplinary field of history. Importantly, as fan studies scholars indicate, this terminology reflects not only differences in practice but also a division along gender lines. Jenkins et al. $(2013,150-1)$ argue that 'transformational fandom [...] seeks to rewrite the texts to better serve fan interests'; these are 'historically "feminine" interests (especially those related to exploring the emotional and erotic relations between characters)'. Further work on these histories must attend closely to this distinction and its relationship to activities taking place, given that $E V E$ 's community — as we have noted potentially the most 'historical' community - is around 97\% male (Carter, et al. 2016, 10). It is significant, also, that there is a body of material which is simply present and as yet unrealised as either history or fanwork. To conceive of this as archive is to recognise its unrealised potential: we see only 'the stories it tells by itself'; we lack those enabled 'through its interaction with the viewer or reader and their consequent re-interpretation, reiteration or re-presentation' (Breakell 2015, 2).

\section{Conclusion}

What, then, does all of this mean for history more generally? A tension exists between the Rankean notion of attention to events as they 'really were' (1885, vii), and what White rather more recently referred to as 'those aspects of the real past which the historical past cannot deal with' (2014, xiv). While lore, it is clear, does not deal in such realness - does not concern 'specifically real events' (White 1990, 45) - player experiences do, and would perhaps fall into that category of the real which the historical cannot accommodate. We 
would argue that, where those experiences concern something which can be understood as an aspect of a shared past (and thus are validated by the community, through the debate around True Stories, for example), they have a claim to (public) historicity, to be a discourse about a past (see Webber 2016, 199). At its heart, public history makes arguments about the past, and through these arguments that past is put to work in a meaningful way. Through these game histories, we can see this meaningfulness demonstrated in the fear that particular 'True' Stories are being deployed as propaganda, or show bias or over-interpretation.

There is history here, then, but not all of this activity is history. Equally, there is fandom here, but not all of this activity is fandom. We might distinguish between the two by thinking of fandom as acts of individual memory contextualised within acts of community, and history as acts of community contextualised within an ongoing narrative of that community. The implications of this are that, when actions cannot be contextualised, they cease to be either history or fandom and, as soon as they can be, they have claims to be both things. We might apply fandom more commonly to the individualistic valuing of moments of the past; replacing, perhaps, the concept of individual memory and experience, the primacy of personal mattering. History is then about selecting the components of the huge variety of personal pasts that matter beyond those people, that matter across and beyond a community; that have meaning beyond the original text.

\section{Reference List}

Anon. 2015. “Anonymous Everquest Stories.” Public History Norrath: An Oral History of Everquest. Accessed 5 March 2017. http://norrath.jhowardhistory.com/eqstories/anonymous-everquest-stories/.

Archive of Our Own. 2018. "Fandoms.” Accessed 11 April 2018. https://archiveofourown.org/media. 
Breakell, Sue. 2015. "Archival practices and the practice of archives in the visual arts." Archives and Records, 36 (1): 1-5.

Brooker, Will, Mark Duffett and Karen Hellekson. 2017. Fannish Identities and Scholarly Responsibilities: A Conversation. London: Routledge.

Carr, E.H. 1990. What is History? 2nd edn. London: Penguin.

Carter, Marcus, Kelly Bergstrom, Nick Webber, and Oskar Milik. 2016. "EVE is Real: How Conceptions of the 'Real' Affect and Reflect an Online Game Community." Well Played, 5 (2): 5-33.

Chapman, Adam, Anna Foka, and Jonathan Westin. 2017. "Introduction: What is Historical Game Studies?” Rethinking History, 21 (3): 358-371.

Click, Melissa A., and Suzanne Scott. 2017. "Introduction." In The Routledge Companion to Media Fandom, edited by Melissa A. Click and Suzanne Scott, 1-5. New York and Abingdon: Routledge.

De Kosnik, Abigail. 2016. Rogue Archives: Digital Cultural Memory and Media Fandom. Cambridge, MA and London: The MIT Press.

Desjardins, Patrick. 2012. "How I Helped Destroy Star Wars Galaxies.” Medium Difficulty, 6 March.

https://web.archive.org/web/20120309033154/http://www.mediumdifficulty.com:80/2 012/03/06/how-i-helped-destroy-star-wars-galaxies/.

Dietz, William C. 2012. Mass Effect: Deception. London: Orbit.

Fanlore. 2018. “Main Page.” Accessed 12 April 2018. https://fanlore.org/wiki/Main_Page.

Fiddle, Mord. 2013. "EVE Lore: Blog Banter 48.” Fiddler's Edge, 8 August.

http://fiddlersedge.blogspot.co.uk/2013/08/eve-lore-blog-banter-48.html.

Gianturco, Alexander (“The Mittani”). 2013. “The Mittani Sends His Regards: Disbanding Band of Brothers." True Stories from the First Decade--EVEOnline.com, 6 May. 
https://web.archive.org/web/20150905220556/https://truestories.eveonline.com/truest ories/ideas/976-the-mittani-sends-his-regards-disbanding-band-of-brothers.html.

Groen, Andrew. 2015. Empires of EVE: A History of the Great Wars of EVE Online. Chicago: Lightburn Industries.

Hardin. 2013. "Operation Deliverance - How Capsuleers conquered Providence for the Amarr Empire." True Stories from the First Decade--EVEOnline.com, 2 May. https://web.archive.org/web/20150922071453/http://truestories.eveonline.com/truesto ries/ideas/830-operation-deliverance-how-capsuleers-conquered-providence-for-theamarr-empire.html.

Hills, Matt. 2002. Fan Cultures. New York: Routledge.

Howard, Josh. 2018. Public History Norrath: An Oral History of Everquest. Accessed 12 April 2018. https://norrath.jhowardhistory.com/.

Jenkins, Henry, Sam Ford, and Joshua Green. 2013. Spreadable Media: Creating Value in a Networked Culture. New York and London: New York University Press.

Jenkins, Keith. 2003. Re-thinking History. London and New York: Routledge. Jordanova, Ludmilla. 2006. History in Practice. 2nd edn. London: Hodder Education. Kean, Hilda and Paul Ashton. 2009. "Introduction." In People and Their Pasts: Public History Today, edited by Paul Ashton and Hilda Kean, 1-20. Basingstoke and New York: Palgrave Macmillan Ltd.

Kohnen, Melanie. 2017. 'Fannish Affect, 'Quality' Fandom, and Transmedia Storytelling Campaigns." In The Routledge Companion to Media Fandom, edited by Melissa A. Click and Suzanne Scott, 337-346. New York and Abingdon: Routledge.

McKee, Alan. 2007. “The Fans of Cultural Theory.” In Fandom: Identities and Communities in a Mediated World, edited by Jonathan Gray, Cornel Sandvoss, and C. Lee Harrington, 88-97. New York: New York University Press. 
nightrapt0r. 2012. "Errors in Mass Effect: Deception (Google Docs).” Reddit, 31 January. https://www.reddit.com/r/masseffect/comments/p411r/errors_in_mass_effect_decepti on_google_docs/.

Organization for Transformative Works. 2018. "What We Believe.” Accessed 6 August 2018. http://www.transformativeworks.org/what_we_believe/

Pearson, Roberta. 2007. “Bachies, Bardies, Trekkies, and Sherlockians.” In Fandom: Identities and Communities in a Mediated World, edited by Jonathan Gray, Cornel Sandvoss, and C. Lee Harrington, 98-109. New York: New York University Press. Ranke, Leopold von. 1885. Geschichten der romanischen und germanischen Völker von 1494 bis 1514. Leipzig: Duncker \& Humblot.

Rosenzweig, Roy and David Thelen. 1998. The Presence of the Past: Popular Uses of History in American Life. New York: Columbia University Press.

Russo, Julie Levin. 2010. "Twansformative? The Future of Fandom on Twitter.” Julie Levin Russo, 23 August. http://j-1-r.org/2010/08/23/twansformative-the-future-of-fandomon-twitter/

Samuel, Raphael. 1994. Theatres of Memory: Past and Present in Contemporary Culture. London: Verso.

Scott, Suzanne. 2013. Battlestar Galactica: Fans and Ancillary Content. In How To Watch Television, edited by Ethan Thompson and Jason Mittell, 320-329. New York and London: New York University Press.

Steedman, Carolyn. 2001. Dust. Manchester: Manchester University Press.

Stevens, E. Charlotte. 2017. "On Vidding: The Home Media Archive and Vernacular Historiography." In Cult Media, edited by Jonathan Wroot and Andy Willis, 143-59. Basingstoke and New York: Palgrave Macmillan. 
Thorrk, Tyrrax. 2013. “Guiding Hand Social Club's UQS contract, or The Heist where Mirial and Ubiqua Seraph have a bad day." True Stories from the First Decade-EVEOnline.com, 6 May.

https://web.archive.org/web/20150921002227/http://truestories.eveonline.com/truesto ries/ideas/1025-guiding-hand-social-clubs-uqs-contract-or-the-heist-where-mirialand-ubiqua-seraph-have-a-bad-day.html.

Tulloch, John. 2007. “Fans of Chekhov: Re-Approaching 'High Culture'.” In Fandom:

Identities and Communities in a Mediated World, edited by Jonathan Gray, Cornel

Sandvoss, and C. Lee Harrington, 110-122. New York: New York University Press.

Vily. 2016. "Vily’s War Log - Part I.” Crossing Zebras, 17 April.

https://crossingzebras.com/vilys-war-log-part-i/.

Warr, Philippa. 2015. “EVE Online’s Historian Talks Battlefleets And Betrayals.” Rock Paper Shotgun, 25 March. https://www.rockpapershotgun.com/2015/03/23/eveonline-andrew-groen-interview/.

Way, Daniel, Tomm Coker, Alejandro Aragón, Federico Dallocchio, and Daniel Warren Johnson. 2014. EVE: True Stories. Milwaukie, OR: Dark Horse Books.

Webber, Nick. 2016. “EVE Online as History.” In Internet Spaceships are Serious Business: An EVE Online Reader, edited by Marcus Carter, Kelly Bergstrom and Darryl Woodford, 189-209. Minneapolis, MN: University of Minnesota Press.

Webber, Nick. 2017. “EVE Online's War Correspondents: Player Journalism as History.” In Fans and Videogames: History, Fandom, Archives, edited by Melanie Swalwell, Angela Ndalianis and Helen Stuckey, 93-110. London and New York: Routledge. White, Hayden. 1973. Metahistory. Baltimore: Johns Hopkins University Press. White, Hayden. 1990. The Content of the Form: Narrative Discourse and Historical Representation. Baltimore: Johns Hopkins University Press. 
White, Hayden. 2014. The Practical Past. Evanston: Northwestern University Press. 